\title{
SPATIAL MATHEMATICAL MODEL OF HEAT TRANSFER IN HUMAN SKIN INFLUENCED BY HEATED UP TO HIGH TEMPERATURES PARTICLE
}

\author{
Nikolay V. Baranovskiy ${ }^{1, \text { a }}$, Andrey S. Solodkin ${ }^{2}$ and Alexandr A. Stuparenko ${ }^{1}$ \\ ${ }^{1}$ National Research Tomsk Polytechnic University, Institute of Power Engineering, 634050, Tomsk, \\ Russian Federation \\ ${ }^{2}$ National Research University “MPEI”, 111250, Moscow, Russian Federation
}

\begin{abstract}
Numerical research results of heat transfer in system "air-heated particle-skin layer" presented. Skin was influenced by heated up to high temperatures particle. The problem is solved in tree-dimensional statement in Cartesian system of coordinates. The typical range of influence parameters of heated particle considered. Temperature distributions in different moments of time obtained. Condition of burn occurrence by heated particle is under consideration in this research.
\end{abstract}

\section{Introduction}

Recently the problem of forest fires has risen as never sharply. Forest fires of catastrophic scales and consequences arise in the various states annually [1-3]. It is enough to recollect mass fires in Indonesia [4,5], Australia [6], Russia [7]. Such fires have led to increase in diseases and death rate of the population. These consequences grow out of pollution of atmosphere by products of forest fuel burning. Also the important factor is destruction of forest stands [8].

Except an economic and ecological damage fires are the reason of thermal defeats of people. The greatest attention at studying of forest fires given to counteraction to burn traumas at people during ignition, for example, developing of the special sheetings used by manufacture of equipment for firefighters $[9,10]$. Thus, heat exchange by means of radiation becomes the central theme of various researchers. However, radiation is only one of mechanisms of heat transfer from the burning centre. Heated up to high temperatures particles which have been taken out from front of a fire [11,12], can get on human skin that is serious danger. The given problem also demands studying, but did not solve till now. Such particles can have the various form, structure and to consist of various materials. Particle parameters the most typical for real forest fire are considered in the given research: the small size, heat of heating and carbonaceous structure. Steel and ceramic particles, characteristic for technogenic fires $[13,14]$ besides, were considered.

Paper purpose is development of spatial mathematical model and numerical research of heat transfer processes at influence by the heated up to high temperatures particle on not protected human skin.

${ }^{\text {a } C o r r e s p o n d i n g ~ a u t h o r: ~ f i r e d a n g e r @ y a n d e x . r u ~}$ 


\section{Physical and Mathematical Statements}

The human skin is rather difficult structure and one have a various texture in different parts of a body. It is possible to separate out three basic layers: epidermis, derma and hypodermic (drawing 1) [15].

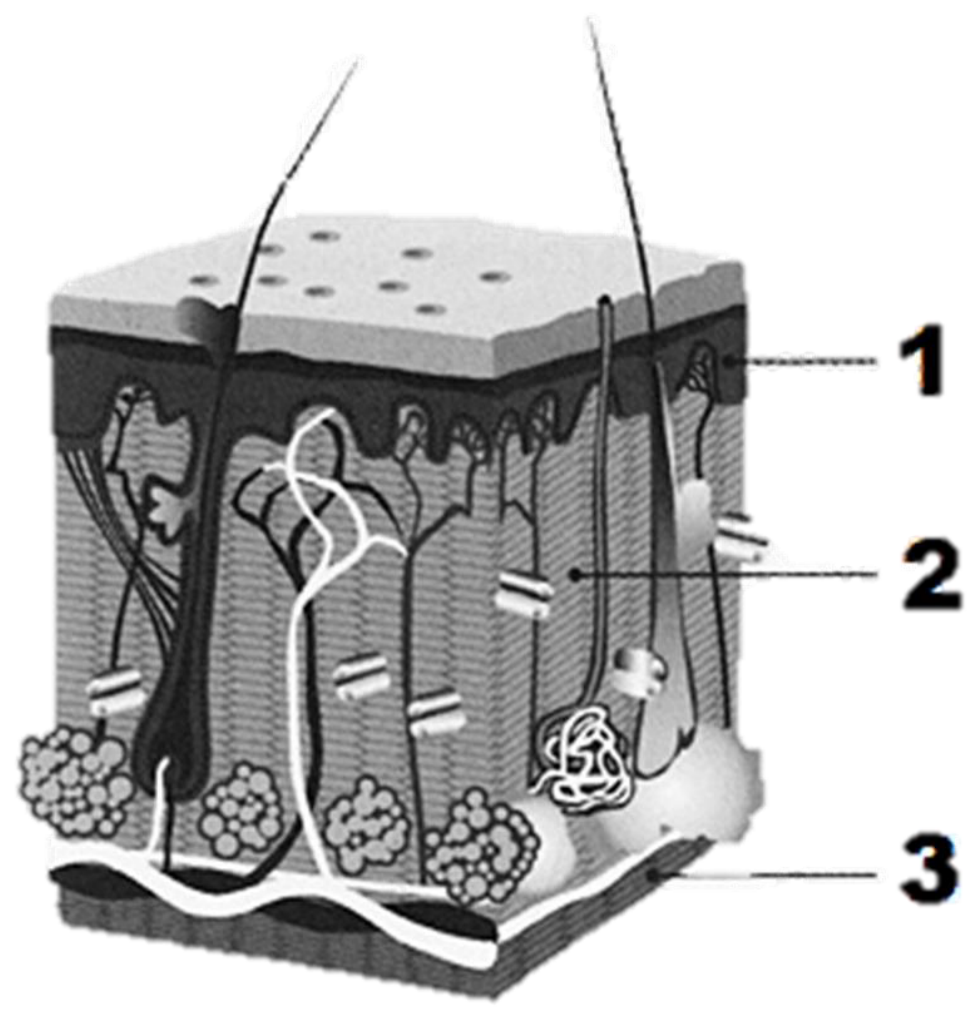

Figure 1. Skin structure: 1 - epidermis, 2 - derma, 3 - hypodermic.

The basic assumptions and suggestions [16,17]:

1. Considered particles are carbonaceous, that corresponds to natural scenarios at thermal decomposition of wood. Ceramic and steel particles also considered (technologic failures).

2. Two-layered system of human skin structure with effective thermophysical characteristics considered.

3. It is supposed, that теплофизические particle and integument characteristics do not depend on temperature.

4. Destruction of human skin tissues under the influence of the raised temperatures neglected.

5. Evaporation of a cellular moisture from human skin also neglected.

6. Conduction is basic mechanism of heat transfer in human skin.

7. Monolithic structure of human skin considered.

Decision area geometry presented on fig. 2. 


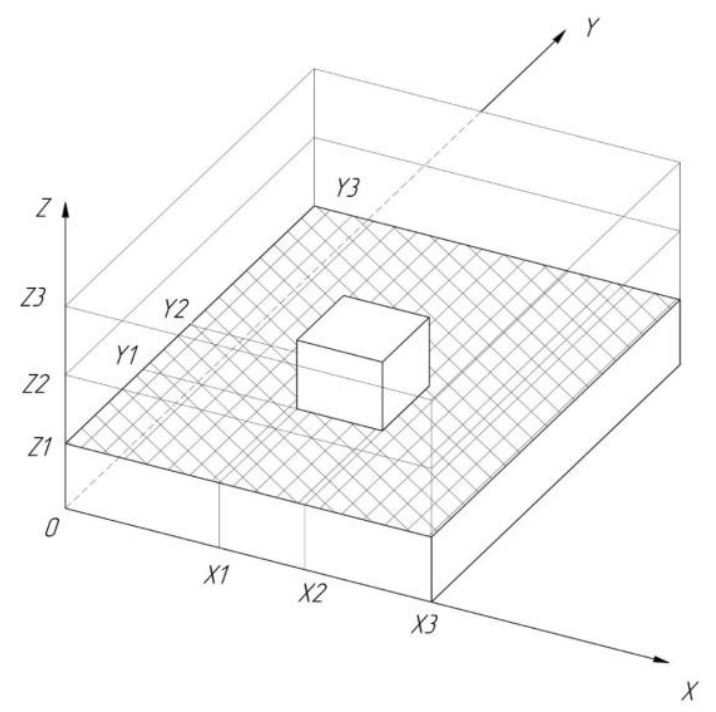

Figure 2. The scheme of decision area.

Basic system of the equations, describing heat transfer processes in system "skin cover-particleair", presented below:

$$
\begin{aligned}
& \rho_{1} c_{1} \frac{\partial T_{1}}{\partial t}=\lambda_{1}\left(\frac{\partial^{2} T_{1}}{\partial x^{2}}+\frac{\partial^{2} T_{1}}{\partial y^{2}}+\frac{\partial^{2} T_{1}}{\partial z^{2}}\right), \\
& \rho_{2} c_{2} \frac{\partial T_{1}}{\partial t}=\lambda_{2}\left(\frac{\partial^{2} T_{2}}{\partial x^{2}}+\frac{\partial^{2} T_{2}}{\partial y^{2}}+\frac{\partial^{2} T_{2}}{\partial z^{2}}\right), \\
& \rho_{3} c_{3} \frac{\partial T_{3}}{\partial t}=\lambda_{3}\left(\frac{\partial^{2} T_{3}}{\partial x^{2}}+\frac{\partial^{2} T_{3}}{\partial y^{2}}+\frac{\partial^{2} T_{3}}{\partial z^{2}}\right),
\end{aligned}
$$

Where $T_{i}, \rho_{i}, c_{i}, \lambda_{i}$ - temperature, density, thermal capacity and heat conductivity. Value of an index $i=1$ corresponds to heated particle, $i=2$ corresponds to an investigated site of a skin, $i=3$ corresponds to air. $t$ - time, $x, y, z$ - spatial coordinates. During the initial moment of time temperatures of a particle, air and приповерхностных fabrics of the person set. Boundary conditions of the first sort exposed on border of decision area. Boundary conditions of 4th sort exposed on border of section of subarea of decision area. Problem solved numerically with use of finite difference method. Finite difference analogues of the differential equations were solved by a marching method [18].

\section{Results and Discussion}

The analysis of the obtained distributions (fig. 3 and 4), allows to ascertain, that eventually there is an intensive cooling of a particle for the account heat exchange at interaction to environment and a skin hypodermic. The obvious hypothesis that the most dangerous to interaction are the particles having more a heat since they have the greatest stock of heat transferred to integuments at contact also proves to be true. The top layer of an investigated site of a skin on depth of an order 0,5-1,5 $\mathrm{mm}$ thus exposed to the most appreciable influence. 
The analysis of the obtained dependences (fig. 5) allows to drawn conclusion, that for the first half-second of contact heated particles with a hypodermic layer of a skin the temperature remains practically invariable. For the next second of interaction growth of temperatures for particles with various initial temperatures occurs to similar speed. The greatest speed of warming up observed in a range from 2 till 5 seconds, then intensity of warming up decreases.

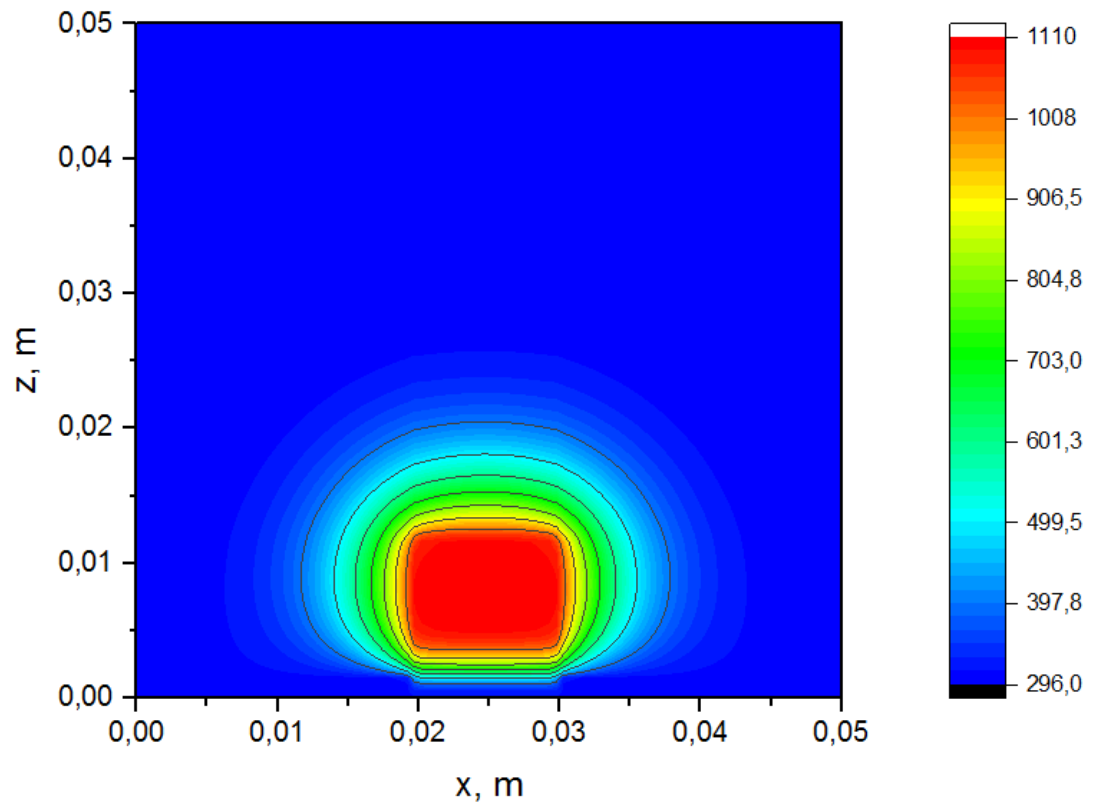

Figure 3. Distribution of temperatures in system a "skin-particle-air" at the moment of time $t=1 \mathrm{~s}$ for a carbonaceous particle at initial temperature $\mathrm{T}=1100 \mathrm{~K}$.

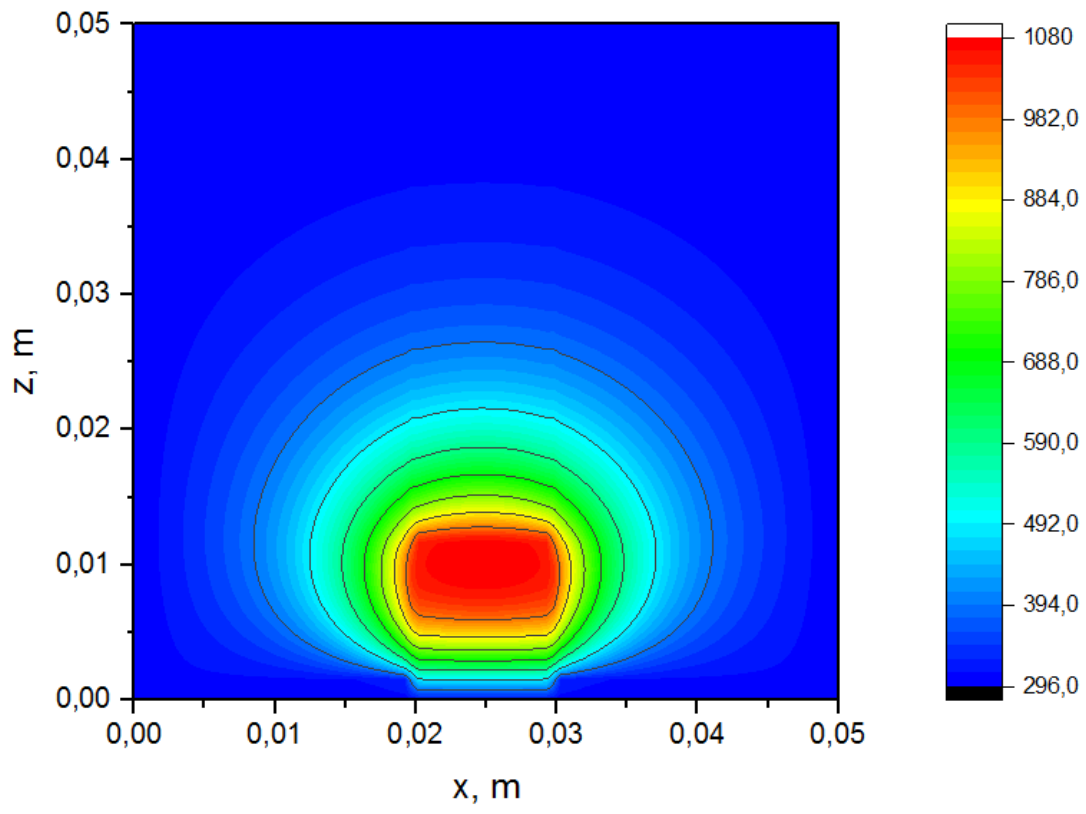

Figure 4. Distribution of temperatures in system a "skin-particle-air" at the moment of time $t=5 \mathrm{~s}$ for a carbonaceous particle at initial temperature $\mathrm{T}=1100 \mathrm{~K}$. 


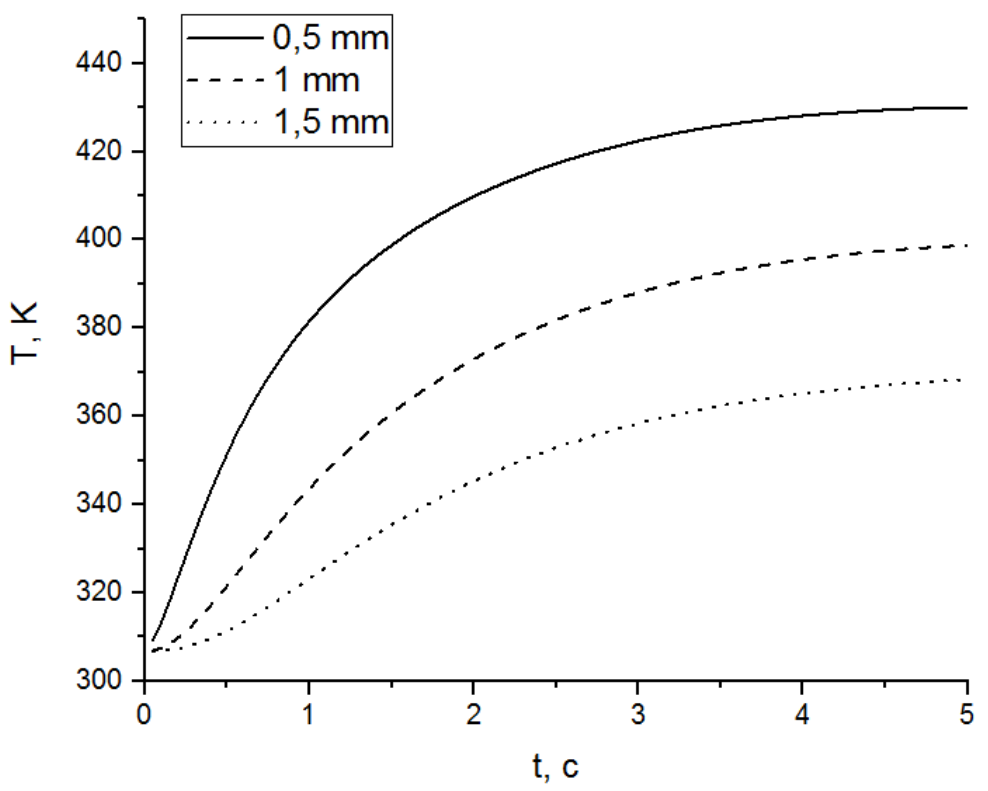

Figure 5. Dependence of skin temperature in the depth of a layer from time of influence for a steel particle at initial temperature $\mathrm{T}=1100 \mathrm{~K}$.

Short-term influence of heated up to high temperatures particles on human skin was accepted in the present work. This assumption corresponds to the scenario of behavior of the person which has no traumas obtained as a result of a fire and is capable to exclude long influence of heated particles on skin.

Dependences of temperature of an integument in the depth of a layer from influence time obtained. Also particles with various initial temperatures were considered. Various distribution of temperature for particles with different initial temperature is natural. The analysis of the presented curves allows to draw a conclusion, that in a current of half-second from the moment of contact of a particle and an integument its temperature in the heart of a layer practically does not vary. The next second the temperature grows practically equally for particles with various initial temperature. In time from 2 seconds till 5 seconds there is the most intensive heating of inside layers of an integument. Then warming up also amplifies, but its rate slightly decreases. Also it is possible to notice, that intensity of heating of a skin a carbonaceous particle much more low, than at steel and ceramic particles at the expense of smaller value of factor of heat conductivity. Temperature of layer near to a skin surface is above for steel and ceramic particles. The maximum temperature of heating observed at contact to a steel particle.

The analysis of temperature distributions shows, that at any temperatures enough a hot particle appreciable influence observed in the top layer of an integument. With increase in a thickness of a considered layer of a skin the temperature effect from contact to a particle decreases. It is natural, that particles with higher temperature can heat up an integument on the higher temperature and influenced in the depth. Also it is necessary to notice, that the particle of carbonaceous structure makes smaller impact on a skin at contact in comparison with steel and ceramic particles.

Proceeding from the aforesaid, it is possible to conclude, that the most dangerous variant from considered for contact to a human skin is the variant with a metal particle. The analysis of dependences confirms the conclusions made on one-dimensional and two-dimensional problems. Dependences have the same appearances, however there are insignificant differences in values, in view of higher accuracy of calculation by consideration of a three-dimensional problem. 


\section{Conclusion}

It is possible to assert, that the decision in one-dimensional statement allows to obtain the exact enough results at research of the processes considered in the given problem. At complication of problem is increase in accuracy of results slightly. However, by consideration of more difficult models, for example at heating of integuments by several particles, use of one-dimensional statement is inadmissible and, accordingly, application of spatial problems is necessary. The obtained results, namely program realizations of mathematical models for heat transfer in system "air-particle-skin", can be used for development of new generation of medical information systems [19,20]. Such systems, in turn, can find application in structures of the Ministry of Emergency Measures, medical institutions and departments of protection works or a civil defense at the industrial enterprises. It is necessary to notice, that development of the complex deterministic-probabilistic approach on the basis of methods of the forest fire danger forecast [21-24], information-computational technologies [25-27] taking into account the developed mathematical models of heat transfer in human skin is possible. Such system will allow to predict as forest fire danger, and as to estimate influence of fires on the persons.

\section{References}

1. Wagtendonk J. W. Van. Fire as a physical process//Fire in California's ecosys tems (2006)

2. Flannigan M. D., Wotton B. M. Canadian Journal of Forest Research, 21, 277 (1991)

3. Larjavaara M., Kuuluvainen T., Rita H. Forest Ecology and Management, 208, 177 (2005)

4. Aditama T.Y. Respirology, 5, 169 (2000)

5. Sastry N. Demography, 39, 1 (2002)

6. Penman T.D., Keith D.A., Elith J., Mahony M.J., Tingley R., Baumgartner J.B., Regan T.J. Biological Conservation, 190, 142 (2015)

7. Mokhov I.I., Chernokulsky A.V. Geography and Natural Resources, 31, 165, (2010)

8. Granzow-de la I., Lloret F., Ruiz J.E., Vandermeer J.H. Forest Ecology and Management, 265, $248(2012)$

9. Raimundo A.M., Figueiredo A.R. Fire Safety Journal, 44, 514 (2009)

10. Monds J.R., McDonald A.G. Applied Thermal Engineering, 50, 593 (2013)

11. Manzello S.L., Cleary T.G., Shields J.R., Yang J.C. Fire and Materials, 30, 77 (2006)

12. Manzello S.L., Cleary T.G., Shields J.R., Yang J.C. International Journal of Wildland Fire, 15, 427 (2006)

13. Baranovskii N.V. Chemical and Petroleum Engineering, 51, 212 (2015)

14. Zakharevich A.V., Strizhak P.A. Journal of Engineering Thermophysics, 22, 157 (2013)

15. Xu F., Lu T.J., Seffen K.A. Journal of the Mechanics and Physics of Solids, 56, 1852 (2007)

16. Baranovskiy N.V., Solodkin A.S. MATEC Web of Conference, 23, (Paper 01008) (2015)

17. Korobkina D.V., Baranovskiy N.V. MATEC Web of Conferences, 19, (Paper 01035) (2014)

18. Samarskij A.A., Nikolaev E.S.method of the decision of the net equations. (1978)

19. Petter S., Fruhling A. International journal of medical informatics, 80, 480 (2011)

20. Goldschmidt P.G. Communications of the ACM, 48, 69 (2005)

21. Kuznetsov G.V., Baranovskiy N.V., Barakhnin V.B. EPJ Web of Conferences, 82, (Paper 01019) (2015)

22. Baranovskiy N.V., Zakharevich A.V., Osotova D.S. EPJ Web of Conferences, 82, (Paper 01020) (2015)

23. Baranovskii N.V., Ni A.E. Journal of Engineering Physics and Thermophysics, 87, 1438 (2014)

24. Baranovskiy N.V., Naumkin A.S. MATEC Web of Conferences, 19, (Paper 01036) (2014)

25. Baranovskiy N.V., Yankovich E.P. Journal of Automation and Information Sciences, 47, 11 (2015)

26. Baranovskiy N.V. Journal of Automation and Information Sciences, 47, 40 (2015)

27. Baranovskiy N V. Cybernetics and Systems Analysis, 51, 471 (2015 